\title{
POSTPRINT
}

\section{Quantitative and Qualitative Research across Cultures and Languages: Cultural Metrics and their Application}

\author{
Wolfgang Wagner \\ Karolina Hansen \\ Nicole Kronberger
}

\begin{abstract}
:
Growing globalisation of the world draws attention to cultural differences between people from different countries or from different cultures within the countries. Notwithstanding the diversity of people's worldviews, current cross-cultural research still faces the challenge of how to avoid ethnocentrism; comparing Western-driven phenomena with like variables across countries without checking their conceptual equivalence clearly is highly problematic. In the present article we argue that simple comparison of measurements (in the quantitative domain) or of semantic interpretations (in the qualitative domain) across cultures easily leads to inadequate results. Questionnaire items or text produced in interviews or via open-ended questions have culturally laden meanings and cannot be mapped onto the same semantic metric. We call the culture-specific space and relationship between variables or meanings a 'cultural metric', that is a set of notions that are inter-related and that mutually specify each other's meaning. We illustrate the problems and their possible solutions with examples from quantitative and qualitative research. The suggested methods allow to respect the semantic space of notions in cultures and language groups and the resulting similarities or differences between cultures can be better understood and interpreted.
\end{abstract}

Keywords:

Methods - Cross-cultural psychology - Meaning - Cultural metric - Quantitative research - Qualitative research

Some decades ago the concept of culture played only a subordinate role in psychology. This prompted Mary Douglas to call culture's place in psychology "a blank space, a

\footnotetext{
W. Wagner $(\bowtie)$ N. Kronberger

Department of Social and Economic Psychology, Johannes Kepler University Linz, Altenberger Straße 69 4040, Linz, Austria

e-mail: w.wagner@jku.at

K. Hansen

University of Warsaw, Warsaw, Poland

W. Wagner

University of Tartu, Tartu, Estonia
} 
highly respected, empty pigeonhole" (Douglas 1982, p. 183). Somehow, culture was considered a residual category, which went into the error variance of quantitative studies (LeVine 1982, p. 67). This situation has changed and nowadays we have a lively and vibrant research interest in the role of culture as an explanatory concept for inter-group and interpersonal differences in social psychology. This renewed interest, however, brought to the forefront a heightened awareness for the old issue of comparability: How and on which level can quantitative data and qualitative texts from culturally diverse respondents be compared?

In the following, it shall be argued that straightforward comparison of measurements (in the quantitative domain) and of semantic interpretations (in the qualitative domain) across cultures easily leads to inadequate results. This is due to the fact that scales, questionnaire items and text produced through interview techniques or open-ended questions have culturally specific meanings, that is, they do not map onto the same semantic space unless otherwise proven. Metaphorically, we call these culture-specific semantic structures 'cultural metrics'. We illustrate this with examples from quantitative and qualitative research. ${ }^{1}$

\section{Cross-Cultural Comparison}

\section{Forms of Ethnocentrism and Bias}

Researching culture has never been an easy exercise for psychology. There are two distinct approaches that deal with this issue: cultural psychology and cross-cultural psychology. Cultural psychology attempts to do justice to the particularities of cultures and their capacity to shape the workings of the psychological faculties (e.g. Greenfield 2000; Shweder 2000). It emphasises local description without comparing psychological notions across cultures. Hence, cultural psychology scholars assume that psychological theories developed in the West do not apply to non-Western cultures unless otherwise proven; thereby they largely avoid classical ethnocentrism.

Comparison between cultures, on the other hand, presupposes locally valid theories as well as cross-cultural equivalence of measurement scales and of the associated variables. A failure to establish equivalence can be called conceptual ethnocentrism. Conceptual ethnocentrism lingers when researchers try to project a theoretical variable or parameter found to be a relevant characteristic in one culture onto a notion in another culture. Such comparison presupposes semantic equivalence of the theoretical concept underlying the variable and its wording, and most importantly, of its category values in the languages of different cultures. If this is not established, a comparison of scale values is not warranted and any comparison may show an ethnocentric bias.

Of course, cross-cultural psychologists "find differences in the meaning of constructs annoying, since such differences make the equivalent measurement of constructs more difficult" (Triandis 2000, p. 188). Their research depends on cross-culturally valid

\footnotetext{
${ }^{1}$ A note on terminology is due here: We follow Quine's (1960) suggestion of the equivalence of culture and language. Particularly in our discussion of qualitative methods we feel free to use both terms as being virtually co-extensive.
} 
dimensions of measurement, but this validity cannot be established by local standardisation of scales. A scale can only be standardised by statistical means after the scale has been conceptually defined, that is, after it has been established that the meaning of the underlying psychological construct is the same and that the same metric applies across cultures. In the following we will give a few examples of - in our opinion-conceptually 'biased' research.

Prime candidates for conceptual ethnocentrism are values and beliefs. For example, persistence appears to be an important cultural value in Hong Kong but not for Illinois undergraduates while being well adjusted is claimed to be valued in both samples. Does this mean that the two samples differ in their evaluation of 'persistence' but not in their perception of 'adjustment'? This cannot be answered by comparing scores on a common scale, even with proper translation. This issue is described in a study by Triandis, Bontempo, Leung and Hui (1990) who show that what is thought of the expression 'being well adjusted' to mean in Illinois English is widely shared among Illinois undergraduates and that what is thought of the Chinese language equivalent of 'being well adjusted' to mean in Hong Kong is widely shared among Hong Kong undergraduates. It is not shown, however, that the cultural 'things' designated by the respective English and Hong-Kong Chinese words 'being well adjusted' are socially and culturally equivalent.

The local values contained in the respective Illinois and Hong Kong understandings of 'being well adjusted' would in fact only be equivalent if it meant in both cases either a) 'to talk, think and behave like others in my group', or b) 'to appear like talking, thinking and behaving like others in my group', or c) 'to talk, think and behave as I wish as long as it does not annoy anybody else in my group'. The expression 'being well adjusted' would not be equivalent if in one sample it meant one thing and in the other sample it meant another thing. For example, being well adjusted in the sense of (c) could very well be a US-American understanding; being well adjusted in the sense of (a) or (b) have more the flavour of an Asian culture (but we admit that this is an educated guess based on a 'sample' of three Asian colleagues from different countries). Even if all three have the same literal translation of 'being well adjusted', the specific content is crucially different.

Suffice to say at this point that conceptual ethnocentrism is not a matter of incorrect translation. Even 'literal' translations rarely capture what an indigenous concept means in the local world and which action implications it has.

\section{Dealing with Bias}

The problems encountered by cross-cultural studies motivated the development of several statistical and other methods developed to keep bias in check. Methodologists identify three types of problems: biases in items, methods, and constructs (e.g. Brislin 2000; van de Vijver and Leung 1997; Woolf and Hulsizer 2011).

Item Bias or translation bias is understood as a measurement artefact at the level of scales and items. It involves inadequate translation or formulation of items as well as the fact that the real-world referent of an item might not exist in one or the other culture being compared. In most cases, though, equivalence can be achieved by back-translation. 
Method Bias refers to the non-equivalence of scale scores across cultures. This might be due to participants' divergent tendencies of scale use, familiarity with a stimulus, differences in physical or cognitive ability, age, as well as differences in the test situations. All of the above can be a problem even within a single culture, for example when comparing data from younger and older adults. Furthermore, social experiences and historical changes can influence metric equivalence.

For example a political regime change, as they occurred in many countries after the collapse of the Soviet Union, may drastically change social relationships and economic conditions that entail adaptive changes in beliefs, attitudes and values opf the people experiencing the transition. Lawson and Saltmarshe (2002) showed this process at work in an Albanian village. The post-communist conditions fostered more individualcentred economic activities by the villagers that also transformed local institutions and with it the meaning systems attached to concepts of clan responsibility for social wellbeing and the importance attached to personal qualities such as honesty and generosity among others.

While item and method biases are problems that can be tackled by adequate and culturally equivalent assessment and measurement procedures, the third, construct bias or conceptual bias is more difficult to overcome. It is at the heart of conceptual ethnocentrism that arises if the theoretical construct under investigation changes its meaning and contents in respective cultures ever so slightly. One suggested remedy is including members of the local culture as investigators. Van de Vijver and Leung (1997), for example, expect members of the cultures under investigation to help in evaluating theoretical concepts from the sides of all involved cultures and not only from a dominant Western perspective. Even though this may help in developing a valid instrument, it is no guarantee, as we will see in some of the following examples. The problem of construct equivalence is at the heart of cross-cultural biases because a theoretical construct with questionable validity across cultures has consequences for the applicability of scales and scale values.

Asian researchers' discontent with what they saw as a Western conceptual bias in psychological theory building resulted in developing indigenous psychologies as a culturally more sensitive approach (e.g. Kim 2000; Yang 2000). This approach helped bringing local psychological concepts to the fore. Its research enriched the theoretical inventory of cross-cultural psychology with variables such as social tightness, complexity, activity, honour and verticality (Triandis 1996, p. 408), even though the translatability of some of these concepts into non-Asian cultures has still to be proven.

\section{Cultural Metrics and the Functional Structure of Cultures}

For the purpose of psychological research, culture can be seen as a semantic structure of meanings, "a pattern of shared attitudes, beliefs, categorisations, self-definitions, norms, role definitions, and values" (Triandis 1996, p. 408f) that look like 'cultural syndromes' that is "an organized body of rules concerning the ways in which individuals in a population should communicate with one another, think about themselves and toward objects in their environments" (LeVine 1982, p. 4). Such a system cannot be divided into separate rules, attitudes, beliefs, categorisations, self-definitions, norms, role definitions, or values without losing the essential meaning inherent in their delicate 
cross-reference with other meanings, cognitions and feeling. Each of these is functionally related to many others (Wagner and Yamori 1999). This is what we mean by the metaphor of a 'metric': A 'cultural metric' is a set of notions, items, symbols, or words that are inter-related and that mutually specify each other's local meaning in a culture or language group. Each element's meaning is determined by its relationship to the other elements forming a pattern of interdependencies.

For example, the simple clause 'He did $\mathrm{x}$ because of $\mathrm{y}$ ' can either be an attribution statement or something else depending on the context. In any case, a linguistic analysis of such a clause is insufficient. For it to be an attribution, it is necessary to prove: that the sentence was uttered in a context which called for an explanation and not just for a free association or a recitation of a text; that '... did x' is a salient activity in the culture, otherwise it would not call for an attribution; that '... because of y' gives a sensible reason in that culture; and that the reason given can be classified as internal or external, stable or unstable. A reason like for example '... because he needed to win' can be internal if conceived as a need or intention, or external, if conceived as a pressure of his trainer in a sports competition. One needs to connect a complex clause such as this one to a whole range of contexts that make up the respective culture before one can call it an interpersonal attribution. In other words, the meaning of an interpersonal attribution is fixed by the functional role it plays in certain cultural contexts and their associated pragmatic conventions.

It should be clear by now that we do not refer to shifts in the shades of meaning that linguistic translation always entails. What we mean is a consequence of the thesis of the 'indeterminacy of translation' (Quine 1969). In its strictest interpretation this thesis maintains that each language and culture posits different sets of objects and maps the world in a specific way. Even if we don't subscribe to a strong 'ontological relativism' we maintain that there is no warrant that psychological and social notions, along with physical objects and even scientific terms (cf. Piew, Sarmiento and Kawasaki 2005) differ between cultures only in shades and not in kind. Their comparability in kind must be established during the research process and before comparison. In other words the researcher needs to establish the cultural metric that is, the 'semantic scaffolding' that a local notion maintains with a set of other terms. Thereby the notion's meaning is 'braced' through its relationship to the other terms. This semantic scaffolding can be operationalized with quantitative data as well as with qualitative text material.

\section{Operationalizing Cultural Metrics}

If we consider culture as comprising systems of beliefs and practices that belong together and that are meaningfully interrelated, dependent measures need to be sets of variables instead of single ones. Only a set of dependent measures in quantitative research allows to gauge the pattern among the variables and the meaning attached to them. In other words, it is the "...use of theoretically motivated, within-group (emphasis in the original) observation as a means of specifying culturally patterned activities that can be used as 'measures'" (Laboratory of Comparative Human Cognition 1979, p. 168).

Bundles of variables as a dependent measure addresses two issues simultaneously. First, it allows comparing statistical interactions between variables instead of the main effect of single variables across cultures. Using bundles of variables obliges the researcher to look at interactions within cultures and to compare these interactions 
between cultures. In the statistical sense, only an interaction found in one culture that is replicated, in another culture allows the conclusion that the effect is shared by those cultures (Campbell 1961). But, as Amir and Sharon (1987) have impressively demonstrated, statistical interactions in experimental data can rarely be replicated across cultures even if they are as similar as Israel and the USA. Second, bundles of variables allow pinning down the local interrelated meanings within a semantic field of cognitive and/or evaluative behaviours. Bundles of dependent measures also address the issue of semantics. It is very difficult if not outright impossible to assess the local meaning of the response to an attitude, value or belief item without reference to other attitudes, values, beliefs or practices. A set of responses on continuous or categorical scales, be they answers to closed questions or word associations to stimuli, can be analysed by non-linear multivariate statistics. The resulting pattern of the responses then gives an impression of the semantic relationships in each culture.

Hence, with quantitative data a cultural metric can be operationalized as a pattern of implicit meanings respondents attribute to a questionnaire item. These meanings determine the relationship of one measure to another measure and of one scale difference to a difference on another scale. Thereby respondents pertaining to the same culture define a metric on the issue in question.

What applies to quantitative data and statistical comparison, applies to some sorts of qualitative comparison as well. Discourse and text are as much embedded in local context as responses to questionnaires. But while quantitative data easily evoke the illusion of being de-contextualised and therefore objective and equivalent across cultural samples, qualitative researchers are more aware of the potential fallacies of context and interpretation (cf. Straub 1999). This does not mean, however, that the problem of semantic equivalence does not apply to the comparison of qualitative data.

Interview transcripts and other qualitative material can be compared across languages and cultures using two approaches. The first one is to translate the transcripts from the cultural groups, to pool them and to analyse them jointly. The second is to analyse and interpret the qualitative material locally through researchers native to the respective culture and language and to compare the results in a second step. Both are being used in the few cross-cultural qualitative studies.

An example of the first approach (pooling and joint analysis) is a study by Hohl and Gaskell (2008) who compared public perceptions of food risks (genetic modifications, pesticides, additives, etc.) across 25 European member states. Data analysis was conducted on free associations with food risks from a Eurobarometer survey of nationally representative samples. The questionnaire was developed using a back translation process and respondents gave their answers in their native languages. However, for the data analysis the authors used the English translations of the answers provided by the European Commission (for another example see also Dahlin and Watkins 2000).

An example of the second approach, that is, local interpretation and subsequent comparison, is a study by (Gibbons et al. 1993). They used pictures of women doing housework and office work drawn by adolescents from three cultures: Guatemalan, Filipino and US-American. Then, they had other adolescents from the same culture content analyse the drawings. Naturally, using pictorial material complicates the comparative problem even further, but by having indigenous coders doing the content analysis of the drawings, they first established a local frame of category interpretation that was later used for between-cultures comparisons. 
The two approaches are quite different in their implications because straightforward translation of the original text is a completely different business than translating interpretations. Translating a natural text from one language to another, besides being uneconomical and laborious, risks that the translation somehow alters the implicit and contextual meanings of propositions, sentences and paragraphs.

Local qualitative analysis of text is less affected by this problem. As the interpretations usually need to be understood by and are discussed with colleagues from other cultures, linguistically and culturally competent researchers doing text analysis on the spot are likely to make implicit and contextual meanings explicit in their interpretations. These interpretations are supposed to capture structural semantic features of text as well as its content on a more general level. That is, in a metaphorical sense, the interpretation is done within the local cultural metric.

Translating interpretations and not the original texts, particularly if the researchers cooperate closely in a face-to-face situation, is a much better warrant of comparability or, in the alternative case, of incomparability, than translation of the original material. Even the failure to prove equivalence of semantic spaces is an interesting result in its own right and can enrich psychology's insight into the variability of mentalities and the functioning of minds in different cultures. These issues are being illustrated in the next sections with examples of research.

\section{Research with Quantitative Data}

In this section we will present three examples of quantitative research that first investigated the local metric before proceeding to comparison. The first example is a straightforward quantitative study on the cross-cultural understanding of work values. The second example is a study on the understanding of war and peace in Spain and Nicaragua. Third, is a study on ethical concerns regarding food in three countries. The later two are 'semi-quantitative' as they are using word-associations and free responses, which are then analysed by statistical means.

\section{Attitude Measures}

The Meaning of Work Research Team (1987) conducted an international comparative study on the meaning of work. The key variable in the research was the work centrality score that was obtained by having respondents" assign a total of 100 points to indicate how important the following areas are in your life at the present time: Leisure, Community, Work, Religion, and Family." The points assigned to Work constituted the work centrality score. It was thought to reflect the relative significance of work in respondents' life space.

The authors state that "when making international comparison, it is important to consider response frequency distributions and averages. This, however, is not sufficient, and in some instances, may lead to erroneous or incomplete interpretations" (Meaning of Work Research Team 1987, p. 221). Consequently, they not only compared the scores of work centrality across several countries, but additionally conducted a non-linear multivariate analysis called quantification on response pattern within each 
sample (Hayashi 1950). This was used to show interrelationships between work centrality and more than 30 items about the respondents' definition of work, their reasons to work, how they feel at work, etc. The result of this procedure is the position of each variable value in a multidimensional space. The closer two categories are mapped in the space, the more they are related. By looking at the trace of the respondents' work centrality scores within each country's space, the meaning of a high or low score can be determined for each culture (Fig. 1).

Note that Fig. 1 depicts only three variables of the study to allow easy visual inspection. Visual inspection of the simplified graphs makes it clear that the meaning of work as expressed by the trace of the centrality index is not the same in Japan as in Germany or in the USA. Germans and Americans assigned a similar meaning to work, but Japanese differed in this respect from the both groups.

By further analysis, the authors show that Japanese scored highest and the US lowest on the work centrality scale. This might lead to the erroneous conclusion that the US workers are less motivated to work than the Japanese. In reality, the response pattern analysis reveals that a moderately high score of the US-sample is associated with placing importance on self-expressive aspects of work. Japanese workers scoring at this moderate level are characterised by trust in others and seeking good interpersonal relations at work; they put interpersonal matters in their workplace first and work second. Finally, the analyses showed that only very low scores indicating a negative view of work that one is forced to do mean the same in the different cultures. Hence, purely quantitative scores are hard to compare and interpret if the researcher cannot ascertain that they have the same meaning in the compared cultures.

\section{Word Associations}

A study by Wagner, Valencia and Elejabarrieta (1996) illustrates a similar problem: The authors investigated the structure of word associations dependent on the context in which they were assessed. Respondents from Spain and Nicaragua produced free associations about international conflict/war.
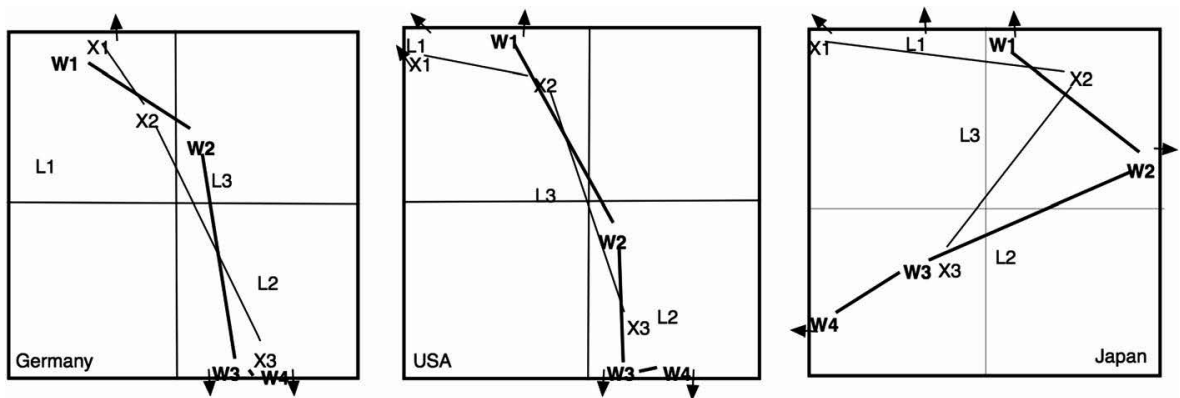

Fig. 1 Trace of 4-point work centrality scale (bold line, W1-W4) an alternative work centrality scale (X1-X3) and a lottery item asking respondents what they would do if they won a lot of money (L1-L3) for Germany, Japan and USA. It is quite obvious that the traces of the work centrality scale W as well as the alternative work centrality scale $\mathrm{X}$ in Western countries are different from the respective trace in Japan. This points to the fact that the categories of the work centrality scale mean different things in the two cultures. Figure adapted from Meaning of Work Research Team (1987), pp. 230, 232, 234 
While the goal of the original research does not concern us here, the data shall serve to illustrate a method which allows to deal with bundles of variables, even if they are free associations and different in the two cultures. The variables were the words that the subjects associated with the stimulus phrase international conflict. Figure 2 shows how the associations about international conflict in Spain and Nicaragua are related to each other.

The two-dimensional solution of a correspondence analysis of the contingency matrix of the words spans a space that can be interpreted as the semantic 'scaffold' of the associations. A cluster-analysis yields two well-connected clusters for each country (in the centre of the figure). Nicaragua's cluster contains five words (destruction, death, hatred, poverty, hunger), Spain's six (the same plus 'war'). The words indicate that the majority of subjects from both countries have similar associations about international conflict. However, the meaning of the word 'war' is grossly different in the two countries, due to a recent US intervention in Nicaragua. It appears in the proximity of different word clusters in the two countries and thus carries a different meaning that would, strictly speaking, prohibit using the word on a measurement scale.

Another study that analysed structures of word associations within and between cultures was a study of ethical concerns regarding food in Finland, Denmark and Italy (Mäkiniemi, Pirttilä-Backman, and Pieri 2011). University students from the

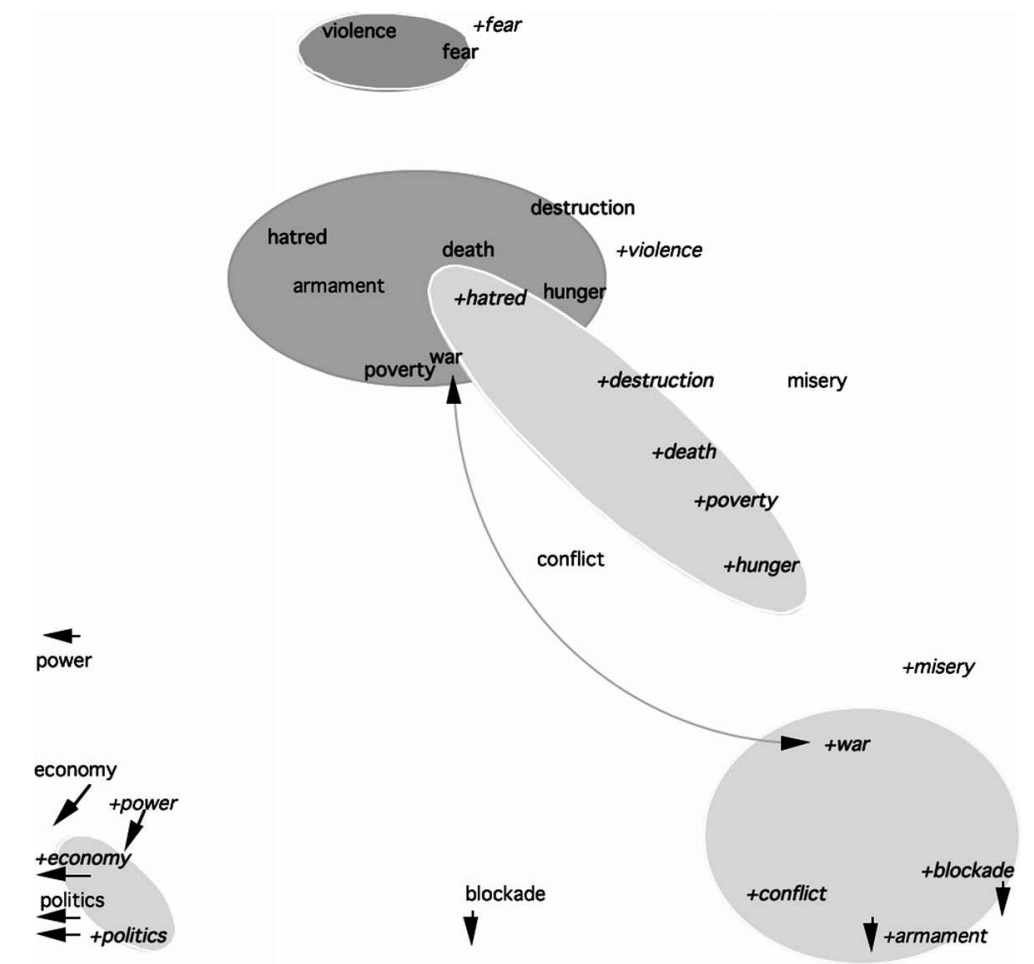

Fig. 2 Semantic space of correspondences between associated words about war and peace for Nicaragua and Spain the different position of the word 'war' in Spain and in Nicaragua. The majority of other word associations aggregate in similar clusters. Data from Wagner, Valencia and Elejabarrieta (1996). Words from Nicaraguan subjects have a ' + ' in front and are in italics. Dark grey clusters: Nicaraguan. Light grey clusters: Spanish. Bold type: Words pertaining to the enveloping cluster. The arc points to the relevant words 'war'. 
aforementioned countries completed a word association task with ethical food and unethical food as stimulus words.

First, each national sample was analysed qualitatively on the basis of similarity in the meanings of the produced associations. The associations were coded into categories independently for each country and in the original languages. Only then, the results of the preliminary categorization were translated into English and discussed during a joint meeting of the researchers. This led to the final categorization system, which was created by the same researchers who negotiated the interpretations. The results indicated fourteen categories of ethical thinking about food (e.g. required/prohibited, natural/unnatural, local/global food). In all countries the categories emerging from the expression 'ethical food' were 'required food' and 'natural food', and emerging from the 'unethical food' was the category 'prohibited food'. The most prevalent differences between countries concerned the role of health, country of origin of food and the descriptions of alimentary products. Some topics were mentioned in all countries, others only in some. Hence, respondents from separate countries did not coincide in their judgements on (un) ethical food. A similar high score of, for example, Italians and Finns on a question about support of subsidising production of ethical food would mean support for different aspects of food production and of different types of food. Therefore, even in the European context the expression ethical food brings to mind different things depending on the country.

\section{Research Using Qualitative Methods}

In the following we present four qualitative studies that recognized different cultural metrics before comparing the results between cultures. One of the studies was about the meaning of biotechnology in six European countries, another one on newspapers reporting on the Bali climate conference, as well as two focus-group studies, where one study is on people's concerns about biotechnology in ten European countries and another one is on the perception of Korean universities.

\section{Written Snippets of Text}

The present example is taken from an international research group investigating the perception of biotechnology in various European countries (Wagner et al. 2002). An open-ended question, in a Eurobarometer survey on representative samples from all member countries of the European Union, asked respondents to write down what comes to their mind when thinking of modern biotechnology. The respondents produced anything between no response and several fully formulated sentences.

This kind of data is influenced by several conditions: First, data collection was run in each country by different sub-contractors and within each country many different interviewers conducted the interviews. Some may have let the respondents write their comment themselves, others may have summarised only the gist of the response. Second, the complete sample comprises responses in 13 languages from 15 different countries.

According to the available groups of collaborators in various countries, the openended responses from six countries (Austria, France, Germany, Norway, Sweden and the United Kingdom) were analysed. We used the program ALCESTE (Reinert 1983, 
1990), which allows analysing a large text corpus automatically and uses descendent hierarchical classification, segmentation and correspondence analysis in its procedure. The algorithm produces matrices of co-occurrences of all words and the words are clustered according to their proximity. If the size of the text-corpus is sufficiently large, the program allows identifying discursive spaces that describe the principal topics being mentioned in the text corpus (for an overview of the procedure see Kronberger and Wagner 2000).

To preserve local meanings and linguistic idiosyncrasies in the data, the texts entering the analysis could, of course, not be translated and merged to a single data file. The principle of respecting the local semantic space demands that each national sample be analysed independently. Hence, in the first step, each of the six national corpora of text data were analysed separately and, in the second step, the resulting cluster solutions were collected and interpreted in comparison. All this was done by the national and language-native researchers or in close collaboration with them.

The clusters found independently in each country's data surprisingly matched quite consistently across countries. Particularly the cluster comprising ideas of meddling and interfering with nature re-appeared in all six countries and can be said to be a shared concern in all of them. This finding is independent of bias that might have been introduced by translating the original responses in a single language and also independent of biased interpretations that might ensue when researchers interpret responses from cultures where they are not native. Research has shown that even same (bilingual) people are to a different extent politically correct depending on the language they are using: They are more politically correct in the language of the culture that stresses political correctness more (Bilewicz and Bocheńska 2010). All of these problems are frequently introduced in cross-cultural research and can be diminished by analysing the data separately in the original languages.

A second example of a study that used separate country analyses of text using ALCESTE, is a study of how the French and German newspapers represent the Bali climate conference from December (Caillaud, Kalampalikis, and Flick 2012). The authors selected texts about the Bali conference from the four most widely read daily newspapers in France and Germany. Using ALCESTE they constructed classes of words, analysed the identified classes and their vocabulary and interpreted the classes in relation to each other. The German corpus was divided into four classes of words, French into three classes. Besides the differences in the number of classes, differences in the ways the conference was described were shown. In the French press, the political and financial aspects of the Bali conference were presented by distinguishing the rich countries from the poor. Although this topic was also present in the German texts, it was less prevalent than in the French texts. In Germany the largest class in the corpus was the human and ethical component related to climate change.

The authors used also a qualitative analysis of the articles and identified different metaphors used by the press in the countries of interest. This analysis corroborated the ALCESTE results. It showed that French media used rather war metaphors and showed conflicts between countries regarding measures to be taken against climate change. In contrast, German media used religious metaphors highlighting a moral dimension of the conference and caring about climate as a duty to all humanity. Had the texts been translated into one language, various biases could have occurred and analysis of metaphors would make less sense. 


\section{Focus-Group Discourse}

This example is from a research that derives from the aforementioned investigation of associations with biotechnology. The European research group on public concerns about biotechnology attempted to corroborate and to understand more profoundly the aforementioned results from an automatic text analysis by conducting focus-group discussions on people's concerns about biotechnology in various European countries (Wagner et al. 2001). Here, as with other methods, it was necessary to observe local meaning systems in the analysis and thus the focus-group transcripts were analysed in their original languages. The study involved ten countries: Austria, Denmark, Finland, France, Germany, Great Britain, Italy, Portugal, Sweden and Switzerland. Each country had a local team of researchers. The research was conducted in seven steps:

After the research teams of all ten countries had convened and agreed on shared interview guidelines, the sampling rules of the focus-group participants and the general procedure, researchers first ran the focus-groups in their own countries approximately in the same period of the year. In most countries the focus-groups were recorded using audio- and video-recording. The transcripts were analysed locally, that is, in each original language and culture, by experienced qualitative researchers. This analysis intended to reveal the most prominent features appearing in the material. Besides topical content, particular attention was paid to metaphors used and the way focusgroup participants referred to different applications of biotechnology.

Second, the results of the first analysis were brought to a joint meeting of all research groups and they were presented and discussed. This workshop allowed identifying universal topics, images and metaphors as well as features of the transcripts that had only local significance. Subsequently, the participants in the meeting developed a grid of those categories and features that were deemed relevant to the research, be they universal or local. The grid allowed to cross-tabulate content categories and discursive features. It was to be used in a second local analysis of the texts and it allowed to enter any local content that was considered relevant by an analyst. The researchers applied this grid to their material in a second analysis of the texts.

Third, after each research group had completed the grids, a final joint meeting of the researchers established the bases for comparison, such that researchers checked their own grid against other grids. This procedure helped to correct interpretational biases and resulted in minor corrections. Finally, for each country a separate table was constructed. The cells contained examples of focus-group text that local researchers considered a typical illustration of the way a certain topic was talked about in the focusgroup sample. The tables were subsequently used for cross-country comparison.

Although qualitative research as the present one reduced some kinds of biases, it is also prone to many problems. First, the selection of the samples is hard if not impossible to parallelise in different countries. Second, qualitative analysts are likely to have their own styles of analysing text even if a shared method is agreed on (as was in this case the grounded theory approach, Strauss 1987). Since qualitative researchers can hardly be "parallelised", the aforementioned approach appeared to be the best common denominator, although it allows for a very high degree of freedom. This freedom, however, was kept under control through the regular meetings. Finally, the biggest problem for professional qualitative researchers is perhaps the fact that a comparative analysis such as this one prohibits analysing the deep structure of the 
texts. Because of the comparative goal, the grids used to present the results were a methodological compromise and automatically lead to simplifications. This contrasts with much of qualitative analysis, which usually strives for an in-depth understanding of texts beyond mere content analysis. Such an in-depth analysis is favoured by cultural psychologists but it would probably not allow for cross-country comparisons.

Another study that compared focus-group discourse from different countries and in different languages analysed how the world class university project in Korea is perceived by participating international scholars and Korean principal investigators (Jang and Kim 2013). Two focus group discussions were conducted: One in Korean with Korean principal investigators and one in English with international scholars. ${ }^{2}$

The analysis was conducted separately for each group and was done in the original languages. The transcribed interviews were (each separately) broken down into words, and the keywords were divided into ten thematic categories by means of a grouping method that automatically clusters nodes according to their patterns of linkages (for details see Jang and Kim 2013). A semantic network analysis was used to visualize the linked concepts. This method is particularly useful in defining core concepts and semantic linkage structures in the text. It can be understood as an automatic and advanced version of content analysis.

The analysis identified themes that were, according to the sequence of linkages among the categories, classified as causes, phenomena, and potential solutions. Figures 3 and 4 represent a sequential classification of the discussed themes within the causes, phenomena and solutions layers. It also shows connections between the themes within and between the layers.

The results showed that while international scholars and Korean principal investigators agreed that the success of the Korean world class universities depends on their mutual collaboration, their core interests and values differed. International scholars placed much weight on the way of dealing with students and on research. Korean principal investigators focused more on the administrative issues, including formal evaluations and regulations. This difference in focus seemed to be an obstacle to understanding and collaboration between Korean and international researchers.

\section{Discussion and Conclusion}

The examples presented in the foregoing sections provide an illustration of how the local metric of cultures and language groups can be respected in comparative research. In the quantitative domain, a social psychological scale needs to be based on an equivalent semantic space if it is used across cultures. Without this warrant, scale scores and what they mean for the respondents cannot be compared. There are statistical methods to check for comparable metrics in such data. Van de Vijver and Leung (1997), for example, suggest parametric methods, such as exploratory factor analysis and subsequent target rotation among others. Alternatively one may use nonparametric methods such as correspondence analysis of word associations as presented

\footnotetext{
${ }^{2}$ There were two participants from the USA, two from Japan and one from Germany. Thus, not for all of them English was their native language, but as they were senior and internationally recognized researchers, their English level was certainly close to native speakers' level.
} 


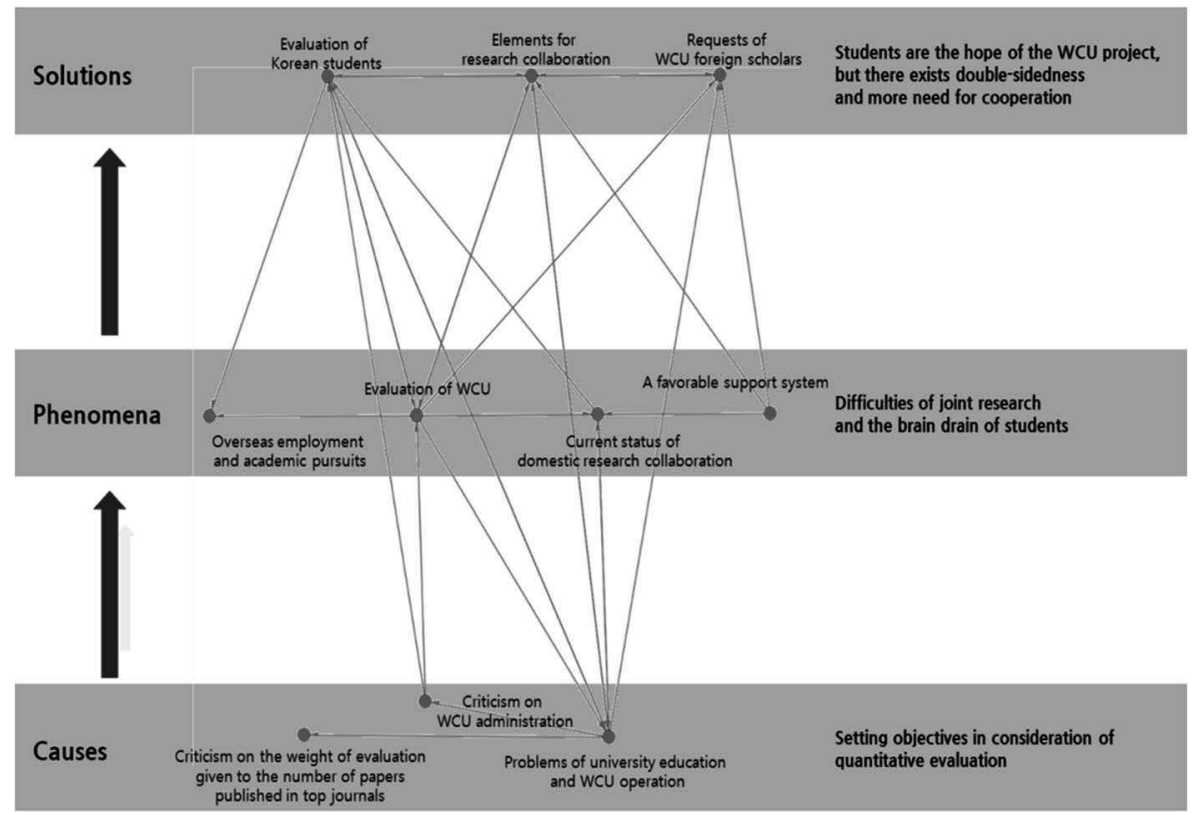

Fig. 3 Sequential relationships by theme for the international scholars sample. From Jang and Kim (2013, p. 733, figure 3), with kind permission from Springer Science+Business Media

here. The validity of these methods does not depend upon precarious parametric assumptions and they allow visualising the internal relationships among a set of

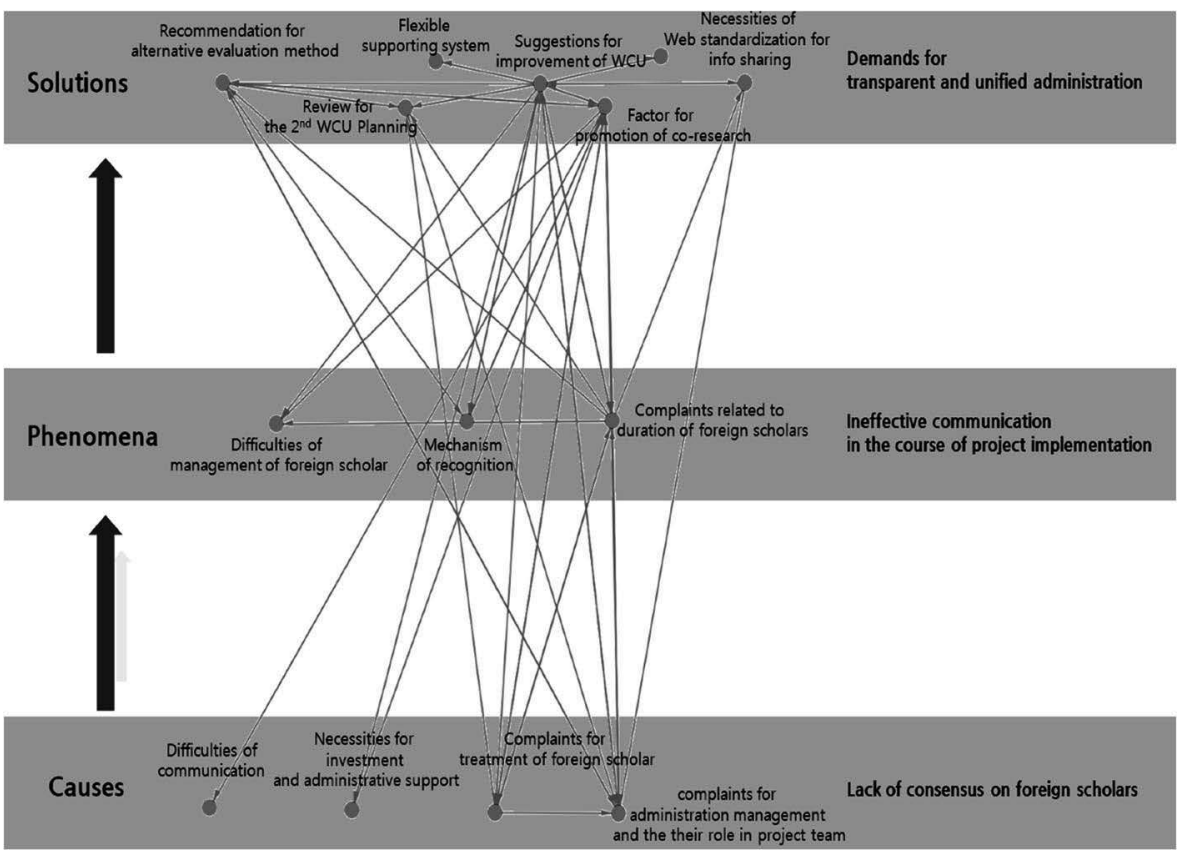

Fig. 4 Sequential relationships by theme for the Korean principal investigators sample. From Jang and Kim (2013, p. 736, figure 5), with kind permission from Springer Science+Business Media 
variables. Therefore, they are more intuitive to the researcher (cf. van de Geer 1993) than elaborate parametric statistics.

ALCESTE is a non-parametric structural method as well. The resulting clusters describe discursive classes, that is, words and phrases that occur in context in a large corpus of text. Using this method on culturally homogeneous text and comparing the obtained cluster solutions in a second step allows establishing similarities and discrepancies of discourse between culture and language groups. ${ }^{3}$

Qualitative 'purists' may view automatic text analysis with suspicion since the method uses structural features of text (i.e. proximity of words) as a means to reconstruct classes of meaning. To check whether the assumption that structure allows to extract meaning is valid, Allum (1998) compared an ALCESTE solution and a manual content analysis and categorisation of the same data set. The results showed a surprisingly good coincidence of the two independently derived results, which corroborates the validity of ALCESTE's automatic analysis.

It might appear as conceptually inappropriate to use the 'quantitative' term metric for qualitative data in cross-country or cross-cultural analysis of focusgroups. We think, however, that the fundamental problem in qualitative comparison is the same as in the quantitative domain. Comparing two data sets presupposes identical meaning of items and scores, that is, a mapping onto a comparable semantic space. With qualitative material this can only be established by doing content-analyses and interpretations locally without prior translation. Only in a second step interpretations and category systems can be translated and brought to bear on a comparative perspective.

Pike's (1967) idea of distinguishing the emic (the insiders') from the etic (the outsiders') approach in cross-cultural psychology was a fruitful one and instigated decades of methodological discussions. Nowadays none of the two is exclusively favoured and the most promising methodological developments have been combinations or integrations of both (e.g. Berry 1989; Helfrich 1999; Van de Vijver and Leung 1997, to name but a few).

In a way, the concept of a cultural metric allows viewing quantitative and qualitative comparative methodology within a framework integrating emics and etics. This perspective needs further analysis as to what degree it may allow to simultaneously consider quantitative and qualitative material bearing on the same phenomenon. Attempts to use both data sources have been made but found to be challenging as our examples show. The debate is open and promises exciting developments in the future.

Acknowledgment Writing of this paper by Karolina Hansen was supported by the post-doctoral internship 'Fuga' awarded to her by the Polish National Science Centre (DEC-2013/08/S/HS6/00573).

\footnotetext{
3 There is an interesting development in statistics called Finite Mixture Modelling that could potentially become a tool for cross-cultural comparison. Building on work by Weller (1984) and Krackhardt (1987), the method models consensus in a way that allows to "identify situations in which multiple distinct but disagreeing beliefs exist between subgroups of individuals" (Mueller and Veinott 2008, p. 899). This method may allow us to understand how cultural differences affect beliefs and attitudes, but the method is still under development and does not yet allow final evaluation (Mueller, Sieck, and Veinott 2007).
} 


\section{References}

Allum, N. C. (1998). A social representations approach to the comparison of three textual corpora using ALCESTE. London School of Economics and Political Science, UK: Unpublished MSc Thesis.

Amir, Y., \& Sharon, I. (1987). Are Social Psychological Laws Cross-Culturally Valid? Journal of CrossCultural Psychology, 18, 383-470.

Berry, J. W. (1989). Imposed Etics, Emics, Derived Etics. International Journal of Psychology, 24, 721-735.

Bilewicz, M., \& Bocheńska, A. (2010). How language affects two components of racial prejudice? A sociopsychological approach to linguistic relativism. In U. Okulska \& P. Cap (Eds.), Perspectives in Politics and Discourse (pp. 385-396). Amsterdam: John Benjamins.

Brislin, R. (2000). Understanding culture's influence on behavior (2nd ed.). New York: Wadsworth.

Caillaud, S., Kalampalikis, N., \& Flick, U. (2012). The Social Representations of the Bali Climate Conference in The French and German Media. Journal of Community \& Applied Social Psychology, 22(4), 363-378. doi:10.1002/casp.1117.

Campbell, D. R. (1961). The mutual methodological relevance of anthropology and psychology. In F. L. K. Hsu (Ed.), Psychological Anthropology. Homewood, Ill: Dorsey.

Dahlin, B., \& Watkins, D. (2000). The Role Of Repetition in the Processes of Memorising and Understanding: A Comparison of The Views of German and Chinese Secondary School Students in Hong Kong. British Journal of Educational Psychology, 70, 65-84.

Douglas, M. (1982). In the Active Voice. London: Routledge \& Kegan.

Gibbons, J.L., Lynn, M., Stiles, D.A., Jerez de Berducido, E., Richter, R., Walker, K. \& Wiley, D. (1993). Guatemalan, Filipino, and U.S.A. adolescents' images of women as office workers and homemakers. Psychology of Women Quarterly, 17, 373-388.

Greenfield, P. M. (2000). Three Approaches to the Psychology of Culture: Where do they come from? Where do they go? Asian Journal of Social Psychology, 3(3), 223-240.

Hayashi, C. (1950). On The Quantification of Qualitatice Data from the Mathematics-Statistical point of view. Annals of Statistical Mathematics, 2.

Helfrich, H. (1999). Beyond the Dilemma of Cross-Cultural Psychology: Resolving the Tension Between etic and emic Approaches. Culture \& Psychology, 5, 131-153.

Hohl, K., \& Gaskell, G. (2008). European Public Perceptions of food risk: Cross-National and Methodological Comparisons. Risk Analysis, 28(2), 311-324. doi:10.1111/j.1539-6924.2008.01021.x.

Jang, D.-H., \& Kim, L. (2013). Framing 'World class' Differently: International and Korean Participants' Perceptions of the World Class University Project. Higher Education: The International Journal of Higher Education and Educational Planning, 65(6), 725-744.

Kim, U. (2000). Indigenous, Cultural, and Cross-cultural Psychology: A theoretical, Conceptual, and Epistemological Analysis. Asian Journal of Social Psychology, 3, 265-288.

Krackhardt, D. (1987). Cognitive Social Structures. Social Networks, 9, 109-134.

Kronberger, N. \& Wagner, W. (2000). Keywords in context: Statistical analysis of text features. In: M. Bauer \& G. Gaskell (Eds.). Qualitative Researching with Text, Image and Sound. A Practical Handbook. London: Sage

Laboratory of Comparative Human Cognition. (1979). What's Cultural About Cross-Cultural Cognitive Psychology? Annual Review of Psychology, 30, 145-172.

Lawson, C. W., \& Saltmarshe, D. K. (2002). The Psychology of Economic Transformation: The impact of the Market on Social Institutions, Status and Values in a Northern Albanian Village. Journal of Economic Psychology, 23(4), 487-500.

LeVine, R. A. (1982). Culture, Behaviour and Personality. New York: Aldine.

Mäkiniemi, J.-P., Pirttilä-Backman, A.-M., \& Pieri, M. (2011). Ethical and unethical food. Social representations among Finnish, Danish and Italian students. Appetite, 56(2), 495-502. doi:10.1016/j.appet.2011.01.023.

Meaning of Work Research Team (1987). International comparison of the relationships between MOW variables. In: Meaning of Work Research Team (Eds.). The Meaning of Working. New York: Academic Press

Mueller, S. T., \& Veinott, E. S. (2008). Paper presented at the Cognitive Science '08. Washington: DC. Cultural mixture modeling: Identifying cultural consensus (and disagreement) using finite mixture modeling.

Mueller, S. T., Sieck, W. R., \& Veinott, E. S. (2007). Cultural metrics: A finite mixture models approach. Klein Associates: Final Research Report.

Piew, L. S., Sarmiento, C. Q., \& Kawasaki, K. (2005). Southeast Asian and Japanese cultural influences on the understanding of scientific concepts. Proceedings of an Intellectual Exchange Project Workshop funded by the Japan Foundation for fiscal year, 2005. Retrieved March 27, 2014 from http://home.e-catv.ne.jp/ kawasaki-knym/files/Reports/7TowardRestration.pdf.

Pike, K. L. (1967). Language in Relation to a Unified Theory of the Structure of Human Behavior. The Hague: Mouton. 
Quine, W. V. O. (1960). Word and Object. Cambridge, MA: MIT Press.

Quine, W. V. O. (1969). Ontological Relativity and Other Essays. New York, NY: Columbia University Press.

Reinert, M. (1983). 'Une méthode de classification descendante hiérarchique: application a l'analyse lexicale par contexte' [A method of descendent hierarchical classification: Application to a lexical analysis per context, French]. Les Cahiers de l'Analyse des Données, 8(2), 187-198.

Reinert, M. (1990). 'ALCESTE. Une méthodologie d'analyse des données textuelles et une application: Aurélia de Gérard de Nerval' [ALCESTE. A methodology for analysing textual data and an application: Aurélia by Gérard de Nerval, French]. Bulletin de méthodologie sociologique, 26, 24-54.

Shweder, R. A. (2000). The psychology of practice and the practice of the three psychologies. Asian Journal of Social Psychology, 3, 207-222.

Straub, J. (1999). Handlung, Interpretation, Kritik. Grundzüge einer textwissenschaftichen Handlungs- und Kulturpsychologie [Action, interpretation, critique. An outline of a text-scientific psychology of action and culture]. Berlin: de Gruyter.

Strauss, A. L. (1987). Qualitative Analysis for Social Scientists. Cambridge: Cambridge University Press.

Triandis, H. C. (1996). The psychological measurement of cultural syndromes. American Psychologist, 51, 407-415.

Triandis, H. C. (2000). Dialectics between cultural and cross-cultural psychology. Asian Journal of Social Psychology, 3, 185-196.

Triandis, H. C., Bontempo, R., Leung, K., \& Hui, C. K. (1990). A method for determining cultural, demographic, and personal constructs. Journal of Cross-Cultural Psychology, 21, 302-318.

Van de Geer, J. P. (1993). Multivariate Analysis of Categorical Data: Applications. London: Sage.

Van de Vijver, F., \& Leung, K. (1997). Methods and Data Analysis for Cross-Cultural Research. London: Sage.

Wagner, W., \& Yamori, K. (1999). Can Culture Be a Variable? Dispositional explanation and cultural metrics. In T. Sugiman, M. Karasawa, J. H. Liu, \& C. Ward (Eds.), Progress in Asian Social Psychology (Vol. 2). Seoul: Kyoyook-Kwahak-Sa Publishers.

Wagner, W., Valencia, J., \& Elejabarrieta, F. (1996). Relevance, discourse and the 'hot' stable core of social representations-A structural analysis of word associations. British Journal of Social Psychology, 35, 331-351.

Wagner, W., Kronberger, N., Gaskell, G., Allum, N., Allansdottir, A., Cheveigné, S., Dahinden, U., Diego, C., Montali, L., Mortensen, A., Pfenning, U., Rusanen, T., \& Seger, N. (2001). Nature in disorder: The troubled public of biotechnology. In G. Gaskell \& M. Bauer (Eds.), Biotechnology 1996-2000: The years of controversy. London: Museum of Science and Industry.

Wagner, W., Kronberger, N., Allum, N., De Cheveigné, S., Diego, C., Gaskell, G., et al. (2002). Pandora's genes - images of genes and nature. In M. Bauer \& G. Gaskell (Eds.), Biotechnology - the Making of a Global Controversy (pp. 244-276). Cambridge: Cambridge University Press.

Weller, S. C. (1984). Cross-cultural concept of illness: Variation and validation. American Anthropologist, 86, 341-351.

Woolf, L. M., \& Hulsizer, M. R. (2011). Why diversity matters: The power of inclusion in research methods. In K. D. Keith (Ed.), Cross-cultural psychology: Contemporary themes and perspectives (pp. 56-72). Malden, MA: Wiley-Blackwell.

Yang, K.-S. (2000). Mono-cultural and cross-cultural indigenous approaches: The royal road to the development of a balanced global psychology. Asian Journal of Social Psychology, 3(3), 241-264.

Wolfgang Wagner is Professor of Social and Economic Psychology at Johannes Kepler University, Linz, Austria, and affiliated with the University of Tartu, Estonia. His research work is on societal psychology, social and cultural knowledge, popularisation of science, racism, fundamentalism, and social representation theory.

Karolina Hansen is Assistant Professor at the Univeristy of Warsaw. She studied psychology and biology at University of Warsaw and did her PhD in psychology at Friedrich Schiller University Jena. She was a visiting researcher at Yale University and a Marie Curie fellow at the Initial Training Network "Language, Cognition \& Gender" at University of Bern. Her research interests are in the fields of social psychology, sociolinguistics, and cross-cultural psychology. They include topics such as language and accent attitudes, stereotyping, gender-fair language, linguistic biases, and cross-cultural differences in social cognition.

Nicole Kronberger is Associate Professor at the Department of Social and Economic Psychology, Johannes Kepler University of Linz, Austria. Her research interests focus on the role of being stereotyped for performance and persistence, social psychological aspects of everyday reasoning about science and technology, metaphoric and imaginative reasoning, and social research methods. 